\title{
Role of Computed Tomography in evaluation of Proptosis
}

\author{
Sharma $P,{ }^{1 *}$ Tiwari $P K,{ }^{1}$ Ghimire $P G,{ }^{2}$ Ghimire $P^{3}$ \\ ${ }^{1}$ Department of Radiodiagnosis and Imaging, Manipal Teaching Hospital, Nepal, ${ }^{2}$ Department of Pathology, Nepalgunj \\ Medical College Teaching Hospital, Nepal, ${ }^{3}$ Department of Radiodiagnosis and Imaging, Nepalgunj Medical College \\ Teaching Hospital, Nepal.
}

\author{
* Corresponding Author: \\ Dr. Prakash Sharma \\ MBBS, MD \\ Department of Radiodiagnosis and Imaging \\ Manipal Teaching Hospital \\ Pokhara, Nepal \\ Email:

\section{Citation} \\ Sharma P, Tiwari PK, Ghimire PG, Ghimire P. Role of \\ Computed Tomography in evaluation of Proptosis. Nepal \\ Journal of Medical Sciences 2013;2(1).34-7.
}

\begin{abstract}
Background: To analyze the role of Computed Tomography in the evaluation of proptosis.

Methods: It is a retrospective review of 30 patients with the history of proptosis who were referred to the department of radiology and imaging for computed tomography of orbit. Computed tomography of orbits was evaluated to assess the nature and extension of the lesion. Final diagnosis was made based on the histopathology, operative findings and clinical outcome. Statistical analysis was carried out with the help of SPSS - 17 to find the accuracy of Computed Tomography.

Results: Thirty patients ranging from three to 73 years were included in the study. Mean age was 35.4 \pm 19.6 years. Male:Female ratio was 2:1. Most common cause of proptosis was inflammation (47\%) followed by tumor. Among the inflammatory causes pseudotumor was the most common type. Other causes of proptosis include tumor (37\%), Vascular (10\%), Infection (3\%) and Trauma (3\%). Accuracy of Computed Tomography in the diagnosis of etiology of proptosis was $86.6 \%$.
\end{abstract}

Conclusion: Computed tomography is the simple, cost effective technique in the evaluation of proptosis with the accuracy of $86.6 \%$. Inflammation was the most common cause of proptosis.

Keywords: Computed Tomography; proptosis; inflamation

\section{Background:}

$\mathbf{P}$ roptosis is defined as any forward displacement or bulging of an eye and is frequently used to describe a change in the position of the globe. The corneal apex is normally 15 to $18 \mathrm{~mm}$ anterior to the lateral orbital rim in adults, with more than $21 \mathrm{~mm}$ or a difference of $2 \mathrm{~mm}$ between the eye positions being abnormal. ${ }^{1}$
Proptosis can result from a variety of disease processes including infective, inflammatory, vascular, neoplastic, traumatic, endocrine lesions and extraorbital lesions. A meticulous history of the patient's ocular and systemic systems, detailed examination and imaging are the key factors in establishing a diagnosis. Computed Tomography (CT) remains very useful because of the inherent natural contrast provided by the presence of structures with widely 


\section{Original Article | Sharma P et al. Computed Tomography in Proptosis}

different attenuation coefficients (fat, bone, fluid, muscle, adjacent air) within a confined space. ${ }^{2}$

This retrospective review was carried out to evaluate the role of Computed Tomography in proptosis.

\section{Methods:}

It is a retrospective review of 30 patients with the history of proptosis that were referred to the department of radiology and imaging for computed tomography of orbit, over the period of one year three months from August 2011 to October 2012. GE spiral CT scanner was used with 3-mm sections in the axial and coronal planes being taken. Coronal sections were initiated at the lateral orbital rim (to lessen exposure to the radiosensitive lens) and continued to the posterior aspect of the optic canals, with the anterior clinoid or dorsum used as landmarks. Prone position was used for taking coronal sections. Scans were obtained both before and after injection of non ionic contrast medium. All patients with globe protrusion $>21 \mathrm{~mm}$ anterior to the interzygomatic line on axial scans at the level of lens were evaluated. Lesions were grossly classified as inflammatory, neoplastic, congenital and traumatic. Final diagnosis was made based on the histopathology/operative findings/ clinical outcome whichever applied in individual cases. Statistical analysis was carried out with the help of SPSS - 17 to find the accuracy of Computed Tomography.

\section{Results:}

Thirty patients between the age group three to 73 years were included in our study. Mean age of the patients was $35.4 \pm 19.6$ years. There was male preponderance with M: F ratio of 2:1. Most of our patients had unilateral proptosis with right side being more predominant (Table 1)

Table 1: Site of Involvement

\begin{tabular}{|c|c|c|}
\hline Site & Frequency & Percent \\
\hline Right & 13 & 43 \\
\hline Left & 11 & 37 \\
\hline Bilateral & 6 & 20 \\
\hline Total & 30 & \\
\hline
\end{tabular}

Most common cause of proptosis was inflammation followed by tumor (Table 2 ).
Table 2: Etiology of proptosis

\begin{tabular}{lcc}
\hline \multicolumn{1}{c}{ Causes } & Frequency & Percent \\
\hline Vascular & 1 & 3 \\
Inflammation & 14 & 47 \\
Infection & 1 & 3 \\
Tumor & 13 & 43 \\
Trauma & 1 & 3 \\
Total & 30 & \\
\hline
\end{tabular}

Pseudotumor accounted for $30 \%$ of the patients with proptosis (Table 3 ).

Table 3: Lesions causing proptosis

\begin{tabular}{lcc}
\hline \multicolumn{1}{c}{ Causes } & Frequency & Percent \\
\hline Pseudotumor & 9 & 30 \\
Graves's disease & 4 & 13 \\
Tolasa Hunt Syndrome & 1 & 3 \\
Meningioma & 2 & 7 \\
Haemangioma & 2 & 7 \\
Dermoid & 2 & 7 \\
Lymphoma & 2 & 7 \\
Retinoblastoma & 1 & 3 \\
Rhabdomyosarcoma & 1 & 3 \\
Leukaemia & 1 & 3 \\
Squamous cell carcinoma & 1 & 3 \\
Adenocarcinoma & 1 & 3 \\
Carotico Cavernous Fistula & 1 & 3 \\
Trauma & 1 & 3 \\
Hydatid Cyst & 1 & 3 \\
Total & 2 & 3 \\
\hline
\end{tabular}

Similarly Graves's disease was seen in 4 patients of proptosis (13.3\%). Accuracy of Computed Tomography in the diagnosis of etiology of proptosis was $86.6 \%$ (26 out of 30 patients were diagnosed correctly by $\mathrm{CT}$ ). 


\section{Discussion:}

The most common cause of proptosis in our study was inflammation. In contrast to this, Masud $\mathrm{MZ}$ et $\mathrm{al}^{3}$ and Sabharwal KK et $\mathrm{al}^{4}$ showed tumor as the most common cause of proptosis. This could be due to the small sample size or less number of tumor patient attending our hospital as most of the tumor patients are being referred to cancer hospital. Pseudotumor and Graves's disease were the two most common inflammatory lesion causing proptosis. In our study pseudotumor accounted for $30 \%$ of the patients of proptosis which is higher than in study by Narula MK et $\mathrm{al}^{5}$ where pseudotumor accounted for $11 \%$ patients of proptosis and Sabharwal KK et $\mathrm{al}^{4}$ where pseudotumor accounted for $8 \%$ patients of proptosis. Pseudotumor was diagnosed based on the non specific radiological findings after excluding other potential causes. All of our patients with pseudotumor presented as unilateral disease.

In our present study, Graves's disease was seen in $13.3 \%$ patients of proptosis which is similar to study by Sabharwal KK et $\mathrm{al}^{4}$ but higher than in the study performed by Narula MK et al. ${ }^{5}$ All of our patients had bilateral disease with inferior rectus being the most common muscle to be involved.

Tolosa Hunt syndrome was seen in one of our patients who was suspected based on asymmetry of the cavernous sinus.

Lymphoma was seen in $6.7 \%$ of our patients of proptosis. In both the patients, lymphoma appeared as a homogeneously enhancing soft tissue density mass lesion in the extraconal compartment. Margo $\mathrm{CE}$ et $\mathrm{al}^{6}$ reported lymphoma as the most common malignant orbital tumor. Similar to this, Sabharwal KK et $\mathrm{al}^{4}$ reported lymphoma as the most common cause of proptosis.

Meningioma was seen in $6.7 \%$ of patients of proptosis as homogeneously enhancing mass arising from the optic nerve sheath and showed tram track sign on axial images. Both the patients with meningioma were diagnosed correctly. Calcification was seen in one of the lesion.

Haemangioma was seen in two of our patients with proptosis, making it $6.7 \%$ of our patients of proptosis. Similar to this, Khan et al found it to be $5.8 \%$ of the total orbital lesions. ${ }^{7}$ In contrast to this Masud ZS et al found haemangioma in only $2 \%$ of the total orbital lesion in the paediatric population. ${ }^{8}$ Cavernous hemangiomas are usually discovered in young to middle-aged adults. The lesions tend to be well encapsulated with distinct margins, are usually intraconal and grow slowly. ${ }^{9}$ Both the cavernous haemangiomas were well encapsulated and intraconal in location and having moderate heterogeneous enhancement.

Rhabdomyosarcoma is the most common primary malignant orbital tumor in childhood with an average age of presentation being 7 years. In our study, patient with Rhabdomyosarcoma presented at a young age of 5 years.

Similar to Sabharwal KK et al, ${ }^{4}$ the most common paraorbital tumor invading the orbit in our study was maxillary carcinoma.

Hydatid cyst was seen in one of our patients of proptosis. It appeared as a well defined cystic lesion within the extraconal compartment.

In our study $3.3 \%$ of the patients with proptosis had caroticocavernous fistula. A carotid cavernous fistula is an abnormal high flow communication between the arterial and venous circulations. They are most commonly posttraumatic in etiology. ${ }^{11}$ Other causes include spontaneous fistulas, possibly related to atherosclerotic disease and rupture of an aneurysm of the intracavernous portion of the carotid artery. ${ }^{11}$ In our patient there was no history of trauma. There was asymmetry and distention of the both the cavernous sinus, congestion and asymmetrical dilation of the superior ophthalmic vein bilaterally suggesting bilateral disease. Carotico cavernous fistula accounted for $2 \%$ and $7 \%$ of the patients with proptosis in studies by Sabharwal $\mathrm{KK} \mathrm{et}{ }^{4}$ and Masud MZ et $\mathrm{al}^{8}$ respectively.

Traumatic lesion accounted for $3.3 \%$ of the patients of proptosis. This is comparable with the study by Sabharwal $\mathrm{KK}$ et $\mathrm{al}^{4}$ and Masud $\mathrm{MZ}$ et $\mathrm{al}^{8}$ where traumatic lesion accounted for $6 \%$ and $5 \%$ of the patients of proptosis respectively. Intraorbital haematoma in the retrobulbar area was seen in one of our patient. In our study accuracy of CT in diagnosing orbital lesions causing proptosis was $86.6 \%$. This is slightly higher than Sabharwal KK et $\mathrm{al}^{4}$ and Mashud et $\mathrm{al}^{8}$ (Table 4).

Table 4: Accuracy of CT in diagnosing proptosis

\begin{tabular}{lcc}
\hline \multicolumn{1}{c}{ Study } & Accuracy & No of patients \\
\hline Present Study & $86.6 \%$ & 30 \\
Sabharwal KK et al & \\
Mahsud et al & $82 \%$ & 50 \\
\hline
\end{tabular}

\section{Conclusion:}

CT is a simple, cost effective method used in the evaluation of proptosis with the diagnostic accuracy of $86.6 \%$. Among 
the various etiologies for proptosis, inflammation accounts for majority of the cases.

\section{Conflict of interest: none}

\section{References:}

1. Khan NH, Moin M, Khan MA, et al. Unilateral proptosis: A Local experience. Biomedica 2004;20:114-6.

2. Massoud TF, Cross JJ. The Orbit. In: Andy Adam, Adrian K. Dixon, editors. Grainger \& Allison's Diagnostic Radiology. 5th ed. China: Elsevier Churchill Livingstone;2008. pp. 1393-1408.

3. Masud MZ, Babar TF, Iqbal A, et al. Proptosis- etiology and demographic patterns. J Coll Physicians Surg Pak 2006;16:38-41.

4. Sabharwal KK, Chouhan AL, Jain S. CT evaluation of proptosis. Indian J Radiol Imaging 2006;16:683-8.

5. Narula MK. Ultrasound evaluation of proptosis. Indian J Radiol Imaging 1994;4:203-206.
6. Margo CE, Mulla ZD. Malignant tumors of the orbit. Ophthalmology 1998;105:185.

7. Khan AA, Amjad M, Azher A, et al. Orbital lesions in Children. Pak J Ophthalmol, 1998;14:86-9.

8. Mashud ZS, Bano S. Diagnostic Role of CT scan in proptosis in paediatric age group. JPMI 18:439-46.

9. Fergenson JM, Mandell N, Abrahams JJ. The orbit. In:Haaga JR,Lanzieri CF Gilkeson RC, editors. CT and MR Imaging of the Whole Body. $4^{\text {th }}$ ed. St. Louis: Mosby;2003. pp. 474-94.

10. Wolfgang D. Radiology Review manual, $6^{\text {th }}$ edition. 2007. Lippincott Williams \& Wilkins

11. Newton TH, Troost BT. Arteriovenous malformations and fistulae radiology of the skull and brain: Angiography. In: Newton TH, Potts DG (eds): Radiology of the Skull and Brain, vol 2. St. Louis, CV Mosby, 1971, pp 2420-565. 